\title{
NOTAS SOBRE O CNE E A QUALIDADE DO ENSINO SUPERIOR
}

\author{
SiLKe Weber*
}

RESUMO: O texto contém algumas notas a respeito da atuação do Conselho Nacional de Educação (CNE), especialmente da Câmara de Educação Superior, desde a sua criação em 1996 pela Lei 9131/ 1996. O CNE é concebido como um espaço social que põe em relação direta agentes da sociedade política, especificamente o Governo, e segmentos da sociedade civil no tratamento de questóes relativas à educação. São destacadas de forma sucinta a sua dinâmica institucional - propostas e conflitos suscitados -, bem como algumas das possíveis repercussōes sobre o ensino superior, em particular, aquelas referentes à expansão da oferta de cursos de graduação e de especialização, bem como à formação de professores.

Palavras-chave: Política educacional. Normas da educação escolar. Qualidade da educação.

\section{Notes on the Brazilian Council of Education (CNe) and the QUALITY OF HIGHER EDUCATION}

ABSTRACT: This paper brings forth some notes upon the action of the Brazilian Council of Education (CNE), especially at the Chamber of Higher Education, since its creation, in 1996, through Law number 9131/1996. The CNE is conceived as a social space that establishes direct links between agents of the political society, specifically the Government, and segments of the civil society as for issues related to education. Its institutional dynamics - proposals and conflicts aroused -, as well as some its possible repercussions not only on higher education, more particularly on the increase of offers of graduate and specialization courses, but also on teacher training are briefly highlighted.

Key words: Educational policies. Standards of school education. Quality of education.

* Universidade Federal de Pernambuco (UfPE). E-mail: silke@elogica.com.br 


\section{Introdução}

$\mathrm{O}$

Conselho Nacional de Educação (CNE) foi instituído pela Lei $\mathrm{n}^{\circ}$ 9.131, de 24 de novembro de 1995, que altera dispositivos da Lei $n^{\circ} 4.024 / 61$ e dá outras providências, com a finalidade de desenvolver "atribuições normativas, deliberativas e de assessoramento ao Ministério da Educação, de forma a assegurar a participação da sociedade no aperfeiçoamento da educação nacional", conforme estabelece o art. $1^{\circ}$, que modificou a redaçăo do anterior art. $7^{\circ}$ da Lei $\mathrm{n}^{\circ} 4.024 / 61$. Como órgão de Estado tem, assim, a tarefa de estabelecer normas congruentes com a legislação em vigor para a educação escolar, nos níveis da Educação Básica e da Educação Superior. Em consonância com esta concepção, teve o seu desenho institucional traçado em duas Câmaras - a de Educação Básica, à qual ficaram afetas as questôes relacionadas à escolaridade obrigatória, às etapas inicial (Educação Infantil) e final, de consolidação e aprofundamento dos conhecimentos adquiridos no Ensino Fundamental (Ensino Médio), às suas diferentes modalidades; e a de Educação Superior, direcionada a estabelecer referências e normas para os diferentes cursos e programas que recobrem a formação em nível superior.

A reflexão crítica sobre o Conselho Nacional de Educação oriundo dessa Lei, entretanto, restringir-se-á à atuação da Câmara de Educação Superior. Este recorte se deve, de um lado, à sua participação nessa Câmara, pelo que dispóe de informações necessariamente privilegiadas e, de outro, à seleção do próprio escopo do texto - relato interpretativocrítico enfocando a sua dinâmica (propostas ali engendradas e conflitos suscitados) - e os supostos impactos sobre o ensino superior. A escolha dos tópicos deste roteiro constitui um dos possíveis desdobramentos da adoção de uma concepção de conselhos em sociedades democráticas como um espaço social que põe em relação direta agentes da sociedade política, especificamente o governo, e segmentos da sociedade civil ${ }^{1}$ no tratamento de questôes relacionadas a uma determinada área de intervenção governamental, no caso, um setor social, o da educação.

Assim, embora constituídos e mesmo dispostos a atuarem como órgãos de Estado, pautados por princípios e posições em relação aos quais haveria um certo acordo ou aceitação em um setor específico, qualquer conselho é, freqüentemente, instado a confirmar prioridades vinculadas a projetos ou programas governamentais e também a interesses de natureza corporativa, além daqueles relacionados especi- 
ficamente ao setor que representa. A atuação do Conselho Nacional de Educação, talvez mais do que a de outras instâncias sociais situadas na esfera pública, é, pois, permeada de tensões e conflitos, que se aguçam em determinadas circunstâncias e se amainam em outras, constituindo a manutenção de coerência nas suas decisões o seu principal desafio. No tocante à Câmara de Educação Superior, nos últimos seis anos, a formulação de um conceito de qualidade da formação em nível superior e o estabelecimento de indicadores compatíveis com essa concepção foram grandes objetos de disputa e de confronto, tal como ficou patente nos momentos cruciais de definições normativas.

\section{Dinâmica institucional}

Os Colegiados de ambas as Câmaras foram constituídos com a participação de entidades ligadas à educação, esforçando-se os seus respectivos integrantes, com concepções próprias de sociedade brasileira democrática, em defender as suas visões sobre educação escolar. Vale anotar, desde o início de seus trabalhos, em 1996, a contraposição a respeito do papel do Estado na materialização da oferta educacional. Para uns, com algumas nuances, a educação escolar constitui direito de todos e dever do Estado; para outros, também com especificidades, esta tarefa se cinge à oferta da escolaridade obrigatória.

Estas visões, de uma ou outra forma, têm que continuamente ser negociadas nas análises e deliberações a respeito da produção individual ou coletiva dos membros da Câmara de Educação Superior expressa como indicações, pareceres sobre questôes referentes à aplicação da legislação, a políticas educacionais em vigor, a temas e problemas educacionais contemporâneos, bem assim corporificada em propostas de resoluçóes, estabelecendo normas e procedimentos, e em deliberações sobre assuntos pertinentes a processos de avaliação.

Desse modo, as referências para as análises e as deliberaçōes de processos relativos ao ensino superior e para a fixação de normas e a formulação de propostas para o sistema federal de ensino resultam quase sempre de amplo, complexo e longo processo de negociação entre pares, processo esse que, dada a natureza da decisão a tomar, pode extrapolar o âmbito da Câmara e envolver, muitas vezes, diferentes instâncias do Executivo responsável pelo setor educacional, com freqüência, segmentos da sociedade civil diretamente com- 
prometidos com a problemática em debate ou, ainda, as próprias instituiçôes de ensino superior interessadas.

Os meios utilizados para a construção das referências mencionadas dependem, certamente, da natureza da decisão a ser tomada. De todo modo, eles podem ser caracterizados como de âmbito interno, a exemplo de sucessivas reuniões envolvendo proponentes e oponentes, ou mesmo o plenário da Câmara, e como de âmbito externo, no caso, conferências, audiências públicas, cujos participantes variam em função da temática em discussão, ou, ainda, reuniōes interinstitucionais. Vale dizer que raramente a Câmara de Educação Superior decide assunto polêmico fazendo recurso ao voto. Trata-se de postura que tem favorecido o enriquecimento e aprofundamento do debate em curso, por permitir a revisão ou confirmação de posições construídas ao longo dos anos de trabalho conjunto mediante a argumentação fundada. É evidente que o instigante clima de discussão ali reinante tem proporcionado as mais diversas interpretaçôes, inclusive a da existência de nítidos blocos no tratamento da questão da educação superior, o que, no entanto, não corresponde à realidade vivida cotidianamente, no período aqui considerado, até porque a busca de uma concepção de qualidade do ensino superior continuava a ser a principal tônica de sua atuação.

É bem verdade que, ao privilegiar indicadores de qualidade nem sempre coincidentes com aqueles adotados por Comissões de Especialistas, em especial, no que se refere à fixação de proporções próprias de titulação docente para certas áreas e à inclusão do desenvolvimento da pesquisa como atividade acadêmica de qualquer instituição de ensino superior, a Câmara de Educação Superior contribuiu para a polarização do debate a respeito desses dois aspectos, sem todavia conseguir esclarecer as razões da controvérsia ou obter apoio para a concepção predominantemente defendida. $\mathrm{O}$ enfrentamento desta polêmica constitui provavelmente, ainda, um dos impactos da atuação da Câmara de Educação Superior no debate atual sobre as características da formação neste nível de ensino.

\section{Algumas repercussões}

Uma outra repercussão da atuação da Câmara de Educação Superior foi certamente a decisão tomada, diante dos quase 5 mil processos sobre os quais teve que se debruçar no início de suas atividades, em 1996, de privilegiar a qualidade da proposta institucional em detri- 
mento da demanda social. Ao contestar este critério freqüentemente adotado pelas Comissóes de Especialistas de então, para avaliar pedidos de autorização de cursos, e percebido como sendo de natureza corporativa, a Câmara deve ter influenciado a forma inadequada que tomou a seguir a expansão do ensino superior no Brasil. Outra decisão da Câmara que também deve ter ensejado a criação desordenada de cursos foi o Parecer $n^{\circ}$ 908/98 sobre cursos de especialização na área profissional, tendo em vista a interpretação apressada que lhe vem sendo dada. A intenção desse parecer era a de incorporar, ao processo formativo de pós-graduação lato sensu, instituições com efetiva tradição de pesquisa aplicada, aproximando-as das universidades de modo que se ampliassem e diversificassem oportunidades de formação continuada qualificadas. $\mathrm{O}$ que se tem assistido, no entanto, é que ao lado dessa perspectiva inovadora há, igualmente, a busca de reconhecimento institucional com vistas à mera obtenção de novos espaços formativos de difícil acompanhamento pelo setor público.

Um outro tipo de repercussão sobre o ensino superior, e mais especificamente sobre a qualidade da Educação Básica, proveio da aceitação, pelo Conselho, da proposta de Formação Pedagógica Complementar para graduados em áreas e disciplinas carentes de professores nos últimos anos do Ensino Fundamental e do Ensino Médio, sem a simultânea instituição de mecanismos regulares de acompanhamento das iniciativas implementadas. Conforme tem sido reiteradamente comprovado, os mais diversos recursos têm sido empregados por algumas instituições de ensino superior com o objetivo de multiplicar as suas chances de licenciar professores. Medidas concretas e imediatas precisam ser tomadas pelo Ministério da Educação, todavia, para estancar iniciativas que contradizem o esforço que vem sendo feito por diversas instâncias envolvidas com o setor educacional, para delinear e salvaguardar uma formação docente que seja caracterizada por um patamar de qualidade compatível com a importância social da sua tarefa profissional.

É, aliás, no tocante à formação de professores que devem ser localizadas as repercussões mais visíveis da atuação tanto da Câmara de Educação Superior como do próprio Conselho. Essas repercussões ocorrem igualmente na reestruturação do sistema formador de nível superior, com a normatização dos institutos superiores de educação (em decorrência dos dispositivos estabelecidos pela Nova Lei de Diretrizes e Bases da Educação Nacional), e nas orientações curriculares, nas dinâmicas formativas e nos conteúdos dos cursos. 
A fixação de parâmetros para a definição da carga horária dos diferentes cursos consiste em um outro tipo de repercussão sobre o ensino superior. No que se refere à formação de professores, a necessária vinculação entre teoria e prática expressa, entre outros aspectos, por intermédio da definição da prática como componente curricular, é quase sempre interpretada como sendo equivalente à prática de ensino. Tratase de uma interpretação reducionista por não incluir como prática outras atividades pedagógicas relevantes do fazer escolar. Isso tem ensejado dificuldades no estabelecimento de acordos ou convênios entre instituições formadoras e os sistemas de ensino. No que concerne aos demais cursos, a indução para a fixação de carga horária que considere a experiência acumulada de formação na área, a tradição internacional, os acordos de equivalência de diplomas e a legislação incidente na educação têm suscitado reações de surpresa diante da possibilidade não percebida da flexibilidade responsável que a legislação oferece.

É a experimentação efetiva de projetos pedagógicos que vai indicar que referências de qualidade de formação de nível superior se imporão na sociedade brasileira. A disputa por projetos de formação nas diversas áreas prosseguirá dando dinâmica própria às propostas formuladas e vivenciadas pelas instâncias formadoras, esperando-se que o Conselho Nacional de Educação, em particular a Câmara de Educação Superior, continue a exercitar a ausculta das demandas e certezas que permeiam o debate acadêmico contemporâneo.

Recife, agosto de 2002.

Recebido e aprovado em agosto de 2002.

Nota

1. No sentido operacional dado por Sérgio Costa (1997) como "o conjunto de associações e formas organizativas que se distinguem de outros grupos de interesse atuantes na esfera política (partidos, lobbies etc.) e da economia (sindicatos, associaçōes empresariais etc.)" com "capacidade de canalizar as atenções públicas para as suas campanhas e pleitos" e identidade constituída no contexto das próprias ações desenvolvidas e cuja vinculação é feita de forma voluntária, tematizando questōes relativas ao cotidiano no artigo "Categoria analítica ou passe-partout político-normativo: notas bibliográficas sobre o conceito de sociedade civil", BIB - Boletim Informativo e Bibliográfico de Ciências Sociais, ANPOCS, v. 43 , n. 1 , p. 3-35.

Educ. Soc., Campinas, v. 23, n. 80, setembro/2002, p. 90-95 